\title{
Pronostic Factors and Survival of Colorectal Cancer in Cameroun: A Retrospective Hospital-Based Study
}

\author{
Jean Paul Engbang1,2, Fabien Bekolo Fouda ${ }^{1,3}$, Ulrich Chanwa1, Marcelin Ngowe Ngowe ${ }^{1,4}$ \\ ${ }^{1}$ Faculty of Medicine and Pharmaceutical Sciences, The University of Douala, Douala, Cameroon \\ ${ }^{2}$ Douala Laquintinie Hospital, Douala, Cameroon \\ ${ }^{3}$ Douala Military Hospital, Douala, Cameroon \\ ${ }^{4}$ Faculty of Medicine and Biomedical Sciences, The University de Yaounde I, Yaoundé, Cameroon \\ Email: jean_pen@yahoo.ca
}

How to cite this paper: Engbang, J.P., Fouda, F.B., Chanwa, U. and Ngowe, M.N. (2021) Pronostic Factors and Survival of Colorectal Cancer in Cameroun: A Retrospective Hospital-Based Study. Open Journal of Gastroenterology, 11, 53-66. https://doi.org/10.4236/ojgas.2021.113006

Received: January 3, 2021

Accepted: March 9, 2021

Published: March 12, 2021

Copyright $\odot 2021$ by author(s) and Scientific Research Publishing Inc. This work is licensed under the Creative Commons Attribution International License (CC BY 4.0).

http://creativecommons.org/licenses/by/4.0/

\begin{abstract}
Background: Colorectal cancer represents a major health problem in the world today, the $3^{\text {rd }}$ most common cancer and the $2^{\text {nd }}$ in terms of mortality. Despite of the fact that the incidence rate remains the lowest in Africa, it is still a provider of a stronger lethality in most western countries. In Cameroon according to WHO 2018, 421 new cases (4.5\% of all cancers) and 451 deaths $(4.3 \%$ of all cancers) were registered. Objective: Determine the prognostics factors and the survival of patients suffering from colorectal cancer followed up in Douala. Patients and Method: This was a retrospective cohort study over a period from January $1^{\text {st }}, 2009$ to December $31^{\text {st }}, 2018$. All patients with histologically proven colorectal cancer, at the gastroenterological, oncological, anatomopathological, radiotherapy and surgery Department of Laquintinie and General Hospitals of Douala were included. The data collected were recorded and analyzed by SPSS version 25 and Excel 2016 statistical computer software. Survival was determined by the Kaplan Meier method and the search for prognostic factors was carried out using the Cox proportional hazards model. The significance level was $\mathrm{p}=0.05$. Results: The median survival was 43 months CI: [35,255 - 50,745]. Survival at 1 year, 2 years, 3 years, 4 years and 5 years was $79.6 \%, 61.5 \%, 46.3 \%, 22.6 \%, 12.2 \%$ respectively. In multivariate analysis, the low degree of differentiation $(\mathrm{HR}=16.278, \mathrm{p}=0.007)$, the presence of synchronous metastases or stage IV patients $(\mathrm{HR}=42.004 ; \mathrm{p}=$ 0.011 ) were independent factors of poor prognosis while curative surgery (HR $=0.172 ; \mathrm{p}=0.001)$ was an independent factor of good prognosis. Conclusion: In our study, the median overall survival was 43 months and the survival at 1 year, 2 years, 3 years, 4 years and 5 years was respectively; $79.6 \%$, $61.5 \% ; 46.3 \% ; 22.6 \% ; 12.2 \%$. The low degree of differentiation and the pres-
\end{abstract}


ence of synchronous metastases were factors of poor prognosis while curative surgery is a factor of good prognosis.

\section{Keywords}

Colorectal Cancer, Prognosis, Survival, Douala

\section{Introduction}

Colorectal cancer ( 1.8 million cases, or $10.2 \%$ of the total) is the third most frequently diagnosed cancer in the world and is responsible for 881,000 deaths, or $9.2 \%$ of the total, making it second in terms of mortality after lung cancer [1]. The incidence rates of CRC (Colorectal cancer) vary from region to region. Countries with the highest incidence rates include Australia, New Zealand, Europe and North America, however, the incidence rates are low in Africa, South Asia and Central America [2] [3] [4] [5] [6]. More than 90\% of colorectal cancer cases occur in people of 50 years and above [7]. A study carried out in Morocco in 2016 showed a slight male predominance with a sex ratio of 1.17 [8]. Clinically, rectal bleeding is the main symptom of colorectal cancer [9]. Complete colonoscopy is the standard procedure for detecting colorectal cancer [10]. Over $90 \%$ of colon and rectal tumors are adenocarcinomas [11]. Treatment of colorectal cancer is based on surgery and chemotherapy, which can be combined with radiotherapy for rectal cancer [12]. The stage of colorectal carcinoma is the most important prognostic factor for the probability of survival [13]. The socio-economic level, the diagnostic delay, the lymph node invasion, tumor residue after surgery, the initial level of carcinoembryonic antigen (CEA), the type and histological characteristics have also been noted as having a considerable influence on the prognosis of the cancer colorectal [14] [15] [16]. The survival of CRC at all stages has increased considerably [17]. Improvements in five-year relative survival have been best in countries with high life expectancies and good access to modern specialized health care [18] [19]. In Africa, few data exist on survival associated with colorectal cancer. A 2009 study in Morocco showed that in subjects with rectal cancer over 40 years, 5-year survival was $40 \%$ [20]. Studies relating to colorectal cancer in Cameroon are few. With an incidence of $2.9 \%$, CRC is the $7^{\text {th }}$ most common cancer in Cameroon behind breast (18.5\%), cervix (13.8\%), Non-Hodgkin lymphoma (11.9\%), prostate (7.3\%), Kaposi sarcoma (6.9\%) [21]. Engbang et al. between 2004 and 2016 found a frequency of $26.01 \%$ for colon cancers, thus representing the 2 nd most frequent tumors after those of the stomach [22]. The evaluation of the management and survival by Ngo Nonga et al. in patients with locally invasive rectal cancer between 2004 and 2007 showed survival at one year of $85 \%$, at 2 years of $60 \%$ and at 4 years- $42 \%$ [23]. Faced with the relative absence of recent data on prognostic factors and the survival of patients with colorectal cancer in our environment, a study on this subject therefore becomes a 
necessity finally to supplement knowledge on this subject for a better evaluation and management of the patient.

\section{Patients and Methods}

This was a retrospective cohort study over a period from January 1, 2009 to December 31, 2018 including all patients with histologically proven colorectal cancer, at the gastroenterological, oncological, anatomopathological, radiotherapy and surgery Department of Laquintinie and General Hospitals of Douala, were retrospectively retrieved from the medical records of those department databases with a $100 \%$ rate of accuracy. We carried out non-probability sampling. Records showing complete clinical examination, indicating the presence of malignant colorectal tumor were included. Patients with other colorectal conditions and histopathological confirmed non-malignant tumors were excluded. The information was collected on a data collection sheet that we designed, pre-tested and readjusted according to the dysfunctions observed. A trained medical staff took part in this collection. The different sociodemographic, clinical, paraclinical, therapeutical and evolutive data were filled in the questionnaires and the patients or their relatives contacted through phone calls in order to know their vital states and also to complete all possible lacking information. The information was registered and processed using SPPS version 25 software and Microsoft Excel 2016. We carried out a descriptive analysis of the studied population, the different associations between clinicopathological variables and tumour location was performed using the $\chi^{2}$ test or Fisher's exact test. Univariate analysis was performed by the survival curves according to the Kaplan-Meier method and the difference in survival was compared statistically by the Log Rank test. Variables statistically significant in univariate analysis were secondarily introduced into the Cox regression model for multivariate analysis. Statistical significance was set at a value of $\mathrm{p}<0.05$.

This work had received an ethical clearance from the Ethics Committee of the University of Douala, who granted us ethical clearance No. 2089 CEI-UDo/01/ 2020/T, to conduct our study in strict compliance with the ethics.

\section{Results}

\subsection{General Characteristics of the Studied Population}

A total of 108 patients with colorectal cancer were included in our study, colon cancer was the most represented with 65 cases (60\%) against 43 cases (40\%) for rectal cancer.

The mean age at diagnosis was $52.84 \pm 13.55$ years (Figure 1 ).

The overall sex ratio was $1(54 / 54)$ (Table 1$)$.

Most patients had no family history of cancer (84.4\%). The mean consultation duration was $10.91 \pm 12.69$ Months. The most common histological type was Lieberkuhnian adenocarcinoma (81.5\%) and majority of the tumours were differentiated tumours (42\%). Stages III and IV were the most represented $(46.3 \%$ and $31.5 \%)$ and majority of our patients had curative surgery. The mean time of 
recurrence and onset of metachronous metastases was $18.23 \pm 14.71$ months and $22.7 \pm 17.2$ months, respectively (Table 2 and Table 3 ).

\subsection{Survival}

As shown in Figure 2, the median overall survival was 44 months with a confidence interval $(95 \% \mathrm{CI})$ of (37.56 - 50.43). The overall survival rates at 1 year, 3 years and 5 years respectively were $79.6 \%, 46.3 \%$, and $12.2 \%$ with a median survival of 43 months.

\subsection{Pronostic Factors}

\subsubsection{Log Rank Test}

As shown in Table 1, no socio-demographic and lifestyle characteristic were

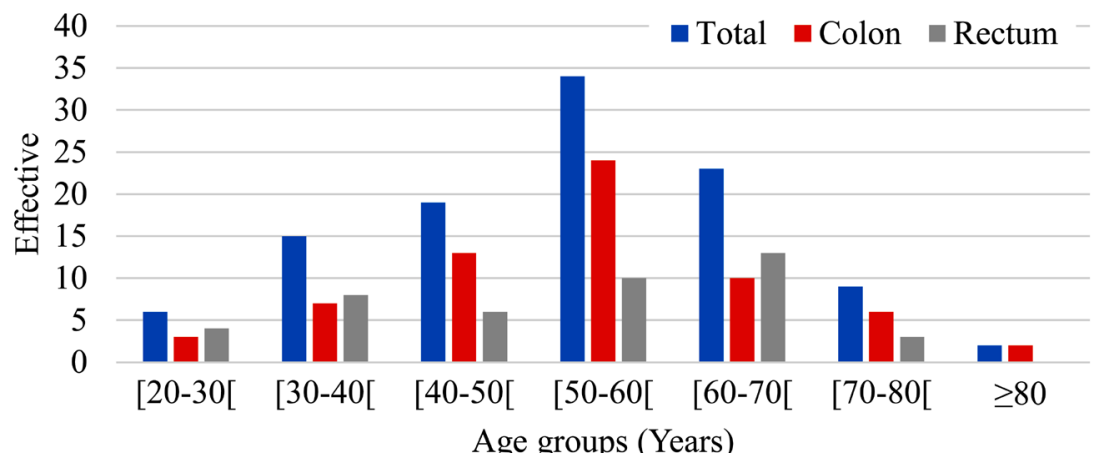

Figure 1. Distribution of patients according to age groups.

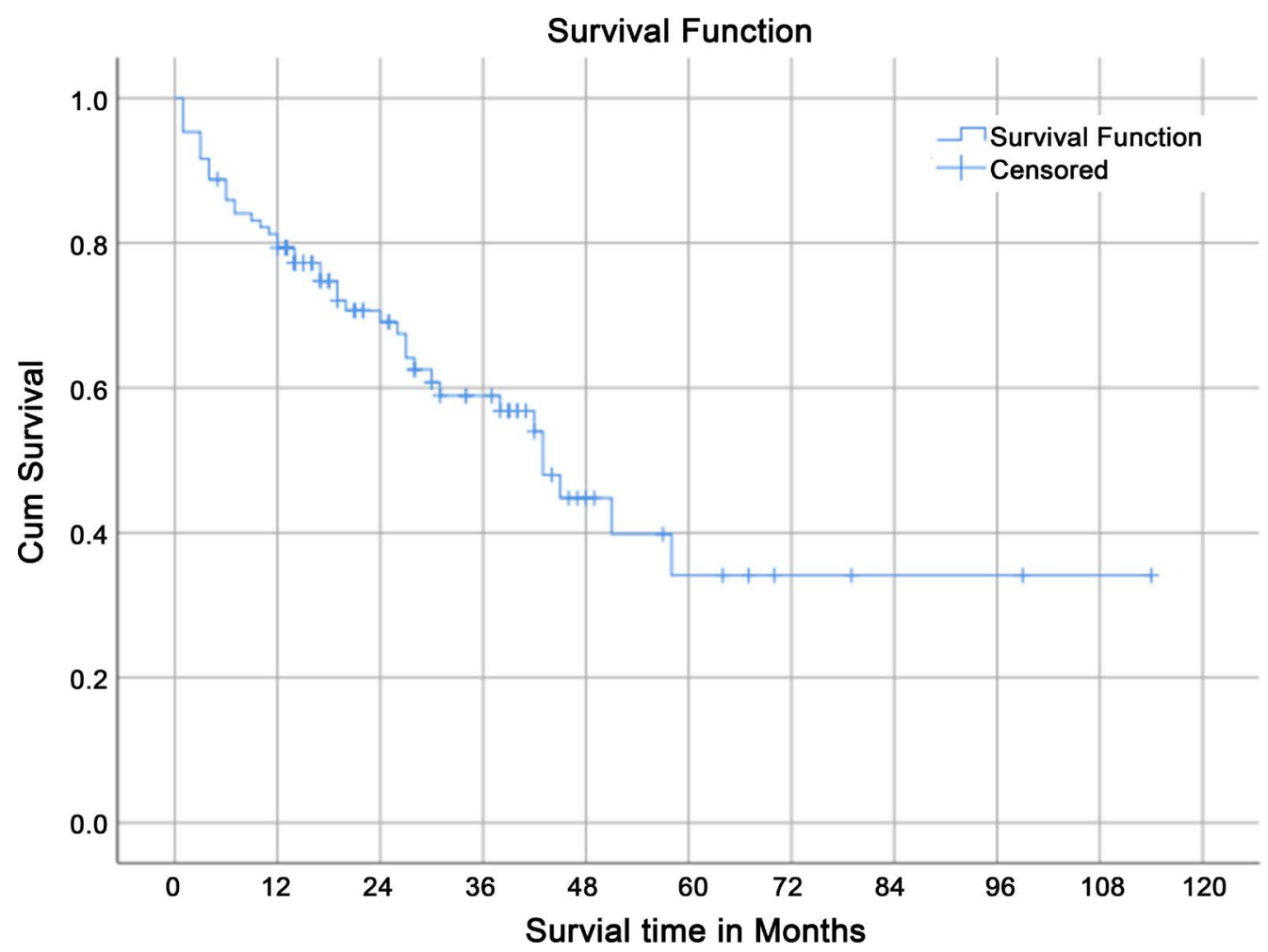

Figure 2. Overall survival curve of the studied population. 
Table 1. Association of socio-demographic and lifestyle characteristics with survival using log rank test.

\begin{tabular}{cccc}
\hline Variable & Frequency $(\mathrm{n}, \%)$ & Median OS (95\% CI) (months) & P-value \\
\hline Age (Years) & & $58(30.567-50.543)$ & 0.616 \\
$\leq 40$ & $23(21.30 \%)$ & $43(30.337-55.663)$ & \\
$>40$ & $85(78.70 \%)$ & & 0.223 \\
Sex & & $42(27.821-56.179)$ & \\
Men & $54(50.0 \%)$ & & 0.245 \\
Women & $54(50.0 \%)$ & $43(29.541-56.459)$ & \\
Mode of discovery & & $38(9.034-66.966)$ & \\
Outpatient & $72(79.12 \%)$ & & \\
Emergency & $19(20.88 \%)$ & $28(15.899-40.101)$ & \\
Comorbidities & & $43(36.204-49.796)$ & \\
Yes & $22(30.14 \%)$ & & \\
No & $51(69.86 \%)$ & & \\
\hline
\end{tabular}

Table 2. Association of clinical and pathological parameters with survival using log rank test.

\begin{tabular}{|c|c|c|c|}
\hline Variable & Frequency $(n, \%)$ & Median OS (95\% CI) (months) & $P$-value \\
\hline ACE rate & & & 0.606 \\
\hline$<5$ & $10(52.63 \%)$ & $42(13.182-70.818)$ & \\
\hline$\geq 5$ & $9(47.37 \%)$ & $38(0.000-82.350)$ & \\
\hline Hemoglobin (g/dl) & & & 0.840 \\
\hline$<12$ & $45(81.82 \%)$ & $43(377.144-48.856)$ & \\
\hline$\geq 12$ & $10(18.18 \%)$ & $45(15.045-74.955)$ & \\
\hline Depth of Tumour Invasion & & & 0.205 \\
\hline $\mathrm{T} 1 / 2$ & $24(38.09 \%)$ & - & \\
\hline T3 & $21(33.33 \%)$ & $28(31.828-58.380)$ & \\
\hline $\mathrm{T} 4$ & $18(28.57 \%)$ & $42(6.891-26.173)$ & \\
\hline Lymph node involvement & & & 0.112 \\
\hline $\mathrm{N} 1$ & $10(19.23 \%)$ & - & \\
\hline $\mathrm{N} 2$ & $27(51.92 \%)$ & $43(27.800-41.501)$ & \\
\hline $\mathrm{N} 3$ & $15(28.85 \%)$ & $42(23.100-56.766)$ & \\
\hline Lymph Node Metastasis & & & 0.041 \\
\hline Yes & 42 & $42(27.254-56.646)$ & \\
\hline No & 10 & - & \\
\hline Distant Metastasis & & & $<0.001$ \\
\hline M0 & $51(75.00 \%)$ & - & \\
\hline M1 & $17(25.00 \%)$ & $24(5.749-42.251)$ & \\
\hline
\end{tabular}


Continued

\begin{tabular}{cccc}
\hline $\begin{array}{c}\text { TNM tumour stage } \\
\text { Stage } 1 / 2\end{array}$ & $12(22.22 \%)$ & $<0.001$ \\
Stage 3 & $25(46.30 \%)$ & $42(34.357-62.361)$ & \\
Stage 4 & $17(31.48 \%)$ & $24(12.616-31.658)$ & \\
Histological type & & $45(30.926-59.074)$ & 0.294 \\
Liberkhunian Adk & 88 & $42(0.362-63.638)$ & \\
Liberkhunian Adk & 13 & & 0.002 \\
Degree of differentiation & & $58(47.823-83.421)$ & \\
well & 34 & $43(33.507-54.120)$ & \\
moderately & 33 & $19(7.223-30.777)$ & \\
poorly & 14 & $51(40.437-83.922)$ & \\
Tumor location & & $43(26.023-59.977)$ & \\
Colon & 65 & & \\
rectum & 43 & & \\
\hline
\end{tabular}

statistically significant association with survival.

As shown in Table 2 , lymph nodes metastasis $(\mathrm{p}=0.041)$ and distant metastasis $(\mathrm{p}<0.001)$ were significantly associated with survival. The median survival time of patient with healthy surgical resection margin was higher (2.08 months) compared to those with invaded (1.25 months). TNM stage was also significantly associated with survival ( $\mathrm{p}<0.001$ ) with patient in stage 4 having the least median survival time (24 months). Another variable significantly associated with survival was degree of differentiation $(\mathrm{p}=0.002)$. The median survival time of patient with well degree differentiation was higher (34 months) compared to those with moderately (33 months) and poorly ( $\mathrm{p}=14$ months) differentiation. There was significant difference with others factors.

Table 3 shows the association of therapeutical parameters with survival. Using cox regression analysis, type of surgery was significantly associated with survival $(\mathrm{p}<0.001)$. The median survival time of patients who underwent curative surgery was higher (82 months) compared to those who did not undergo chemotherapy (12 months) and those who underwent palliative surgery (14 months). Surgical resection, neoadjuvant and adjuvant radiotherapy, neoadjuvant and adjuvant chemotherapy, were statistically not associated with survival $(p>0.05)$.

\subsubsection{Multivariate Analysis (Cox Regression)}

According to the cox regression analysis, poor differentiation $(\mathrm{HR}=16.278, \mathrm{p}=$ $0.007)$, TNM tumor stage $4(\mathrm{HR}=42.004, \mathrm{p}=0.011)$ and curative surgery $(\mathrm{HR}=$ $0.172, \mathrm{p}=0.001)$ were variable that were significantly associated with survival. It is important to notice that curative surgery was the only factor of good prognosis (Table 4). 
Table 3. Association of therapeutical parameters with survival using log rank test.

\begin{tabular}{|c|c|c|c|}
\hline Variable & Frequency $(n, \%)$ & Median OS (95\% CI) (months) & P-value \\
\hline Surgical resection margin & & & 0.478 \\
\hline Healthy & 23 & $58(30.785-85.215)$ & \\
\hline Invaded & 9 & - & \\
\hline Type of surgery & & & $<0.001$ \\
\hline Curative & 82 & $51(36.757-65.243)$ & \\
\hline Palliative & 14 & $27(14.761-39.239)$ & \\
\hline Non operate & 12 & $9(1.299-16.701)$ & \\
\hline Neoadjuvant radiotherapy & & & 0.489 \\
\hline Yes & 11 & - & \\
\hline No & 69 & $51(36.715-65.285)$ & \\
\hline \multicolumn{4}{|l|}{ Neodjuvant Chemotherapy } \\
\hline Yes & 14 & $45(39.288-49.621)$ & 0.329 \\
\hline No & 66 & $42(36.167-65.633)$ & \\
\hline Adjuvante radiotherapy & & & 0.793 \\
\hline Yes & 17 & $58(16.938-99.062)$ & \\
\hline No & 63 & $43(36.715-65.285)$ & \\
\hline Adjuvant Chemotherapy & & & 0.310 \\
\hline Yes & 56 & $51(41.012-60.6988)$ & \\
\hline No & 24 & $27(27.719-46.747)$ & \\
\hline
\end{tabular}

Table 4. Association of different characteristics with survival using Cox regression analysis.

\begin{tabular}{ccccc}
\hline \multirow{2}{*}{ Variables } & HR & \multicolumn{2}{c}{ IC 95\% } & \multirow{2}{*}{ p } \\
\cline { 3 - 4 } & & Min & Max & \\
\hline Poor differentiation & 16.278 & 2.149 & 123.309 & 0.007 \\
Synchronous metastases (Stage 4) & 42.004 & 4.632 & 380.920 & 0.011 \\
Curative surgery & 0.172 & 0.032 & 0.923 & 0.001 \\
\hline
\end{tabular}

\section{Discussion}

The median overall survival in our study was 43 months, similar results were found by Mesli et al. in 2015 in Algeria (40 months), Mehrkhani et al. in 2009 in Iran (42.8 months), Joachim et al. in 2019 in Martinique (3.7 years) [24] [25] [26]. A longer median survival were found by Shan et al. in China in 2017, Spano et al. in France in 2004, they found respectively 69.5 and 61.7 months [27] [28]. Others found shorter, such as Carlomagno et al. in 2018 in Italy (31.9 months), Arfa et al. in Tunisia in 2006 (20 months), Yeboah et al. in Ghana in 2018 (15 months) [29] [30] [31].

Survival at 1 year was $79.6 \%$, similar to our results were that of Ngo Nonga et al. in Cameroon in 2006 who found 60\% and Joachim et al. in 2019 in Martini- 
que,74.6\% [23] [26]. In Western and Maghreb countries, one-year survival was greater as found by Shan et al. in China in 2017 (97.7\%), Chou et al. in Tailand in 2017 (81.5\%), Fernandez et al. in 2016 in Spain (85.9\%), Arfa et al. in Tunisia in 2006 (92.8\%) [27] [30] [32] [33]. In West Africa survival at one year was shorter as found by Gbessi et al. in Benin in 2014: 57.7\% and Yeboah et al. in Ghana in 2018, 64\% [31] [34].

The 3-year survival was $46.3 \%$, similar to the results of Arfa et al. in Tunisia in 2006 (44.8\%), unlike Shan et al. in China in 2017, Chou et al. in Tailand in 2017, Fernandez et al. in 2016 in Spain, who found longer survival times of 87.4\%, $64.3 \%, 65.1 \%$ respectively and Yeboah et al. in Ghana in 2018 who found a shorter three-year survival at 21\% [27] [30] [31] [32] [33].

The 5-year survival was $12.2 \%$ similar to the results of Ouedraogo et al. in Benin in 2019, Yeboah et al. in Ghana in 2018, who found respectively $17 \%$ and 16\% [31] [35]. But Shan et al. in China in 2017, Kwon et al. in 2012 in Korea, Tamakoshi et al. in Japan in 2017, Fernandez et al. in 2016 in Spain, found longer survival times, respectively 72.9\%; 71.4\%; 73\%; 50.5\% [27] [33] [36] [37]. Konaté et al. in Senegal in 2012, Chalya et al. in Tanzania in 2011, for their part found shorter survival times of 5\%, 3\% respectively [38] [39].

We did not find a significant difference in survival depending on tumor location ( $\mathrm{p}=0.194)$. Results similar to those found by Powel et al. in 2012 in England ( $\mathrm{p}=0.427)$, Fernandez et al. in 2016 in Spain ( $\mathrm{p}=0.379)$ [33] [40]. This could be explained on the one hand by the fact that the rectum and the colon have a similar anatomical and histological constitution and the various corresponding cancers present themselves at the anatomoclinical level in a fairly similar manner with almost identical management and comparable evolution.

In general, a better survival in the short, medium and long term has been noticed in Europe and in Asia meanwhile a lower survival is noticed in Africa, especially in West and Southern Africa. This phenomenon can be explained on one hand by more difficult socioeconomic conditions, later consultation with higher rates of complicated and metastatic forms and on the other hand by quality, accessibility of care and better compliance in the West.

In our study, in univariate analysis, age was not a prognostic factor $(\mathrm{p}=$ 0.616). Data in the literature are divergent with regard to age as a prognostic factor. On the one hand, some were found as a prognostic factor in particular Arfa et al. in Tunisia in $2006(\mathrm{p}=0.019)$, Yeboah et al. in Ghana in 2018 ( $\mathrm{p}=$ 0.241) [30] [31]. Unlike Chou et al. in Tailand in 2017 ( $\mathrm{p}<0.001)$, Mehrkhani et al. in 2009 in Iran ( $<$ 0.0001), and Joachim et al. in 2019 in Martinique ( $<$ < 0.001 ) [25] [26] [30]. This discrepancy could be explained by the fact that early cancers are more aggressive and more frequent in some regions than in others.

In univariate analysis, the ACE rate was not a prognostic factor $(\mathrm{p}=0.606)$, our results are similar to those of Carlomagno et al. in 2018 in Italy $(\mathrm{p}=0.31)$ and contrary to those of Arfa et al. in Tunisia in 2006 ( $\mathrm{p}=0.024)$, Kwon et al. in 2012 in Korea ( $\mathrm{p}<0.001)$, Mehrkhani et al. in 2009 in Iran ( $\mathrm{p}=0.021)$ [25] [29] 
[30] [36]. The small size of our sample would certainly have limited the analysis of the ACE rate as a prognostic factor.

In univariate analysis, the degree of differentiation was a prognostic factor ( $\mathrm{p}$ $=0.002$ ). The results were similar to those found by Arfa et al. in Tunisia in 2006 ( $\mathrm{p}=0.019)$, Kwon et al. in 2012 in Korea $(\mathrm{p}=0.003)$, Zou et al. in China in 2016 $(\mathrm{p}=0.014)$, Rosenberg et al. in Germany in 2008 ( $\mathrm{p}<0.001)$ [30] [36] [41] [42]. In multivariate analysis, the low degree of differentiation was an independent factor of poor prognosis ( $\mathrm{p}=0.007$; $\mathrm{HR}=16.278$ ) as were also found by Arfa et al. in Tunisia in $2006(\mathrm{p}<103, \mathrm{HR}=3.4)$ and Rosenberg et al. in Germany in $2008(\mathrm{p}<0.001 \mathrm{HR}=2.29)$ [30] [42]. This could be explained by the fact that the more the tumor cells are different from normal cells, the higher their malignancy.

Concerning lymph node involvement, in univariate analysis, it was a prognostic factor $(\mathrm{p}=0.041)$. Our results are similar to those found by Yeboah et al. in Ghana in 2018 ( $\mathrm{p}<0.001)$, Zou et al. in China in 2016 ( $\mathrm{p}<0.001)$, Rosenberg et al. in Germany in $2008(\mathrm{p}<0.001)$, Spano et al. in France in $2004(\mathrm{p}=0.01)$ [28] and Mehrkhani et al. in 2009 in Iran $(\mathrm{p}=0.016)$ [25] [28] [31] [41] [42]. But those of Kwon et al. in 2012 in Korea ( $\mathrm{p}=0.852)$ were different [36]. Our results could be explained by the fact that the presence of tumor cells at the lymph node level is a sign of a more marked progression of the disease and therefore of a possible dissemination in the body.

In univariate analysis, the finding of synchronous metastasis was a prognostic factor ( $<$ 0.001). Our Results are similar to most of the data in the literature and in particular Yeboah et al. in Ghana in 2018 ( $\mathrm{p}=0.0001)$, Arfa et al. in Tunisia in 2006 ( $\mathrm{p}=0.026)$, Zou et al. in China in 2016 ( $\mathrm{p}<0.001)$, Rosenberg et al. in Germany in 2008 ( $\mathrm{p}<0.001)$, Spano et al. in France in $2004(\mathrm{p}=0.007)$, Mehrkhani et al. in 2009 in Iran (p < 0.0001) [25] [28] [30] [31] [41] [42].

The tumor stage in univariate analysis, was a prognostic factor $(\mathrm{p}<0.001)$. Our results are similar to those found by Yeboah et al. in Ghana in 2018 ( $\mathrm{p}=$ 0.0001), Kwon et al. in 2012 in Korea ( $\mathrm{p}<0.001)$, Zou et al. in China in 2016 ( $\mathrm{p}$ $<0.001)$, Powel et al. in 2012 in England ( $<$ 0.001), Fernandez et al. in 2016 in Spain ( $\mathrm{p}<0.001)$ and Mehrkhani et al. in 2009 in Iran ( $<0.0001$ ) [25] [31] [33] [36] [40] [41]. In multivariate analysis, stage IV was an independent factor of poor prognosis $(\mathrm{p}=0.011 ; \mathrm{HR}=42.004)$ as were also found by Kwon et al. in 2012 in Korea $(\mathrm{p}=0.022 ; \mathrm{HR}=2.147)$, Spano et al. in France in $2004(\mathrm{p}=0.03)$ and Joachim et al. in 2019 in Martinique ( $\mathrm{HR}=3.7 ; \mathrm{p}<0.001)$ [26] [28] [36]. We think that stage 4 patients present a more marked progression of the disease with distant dissemination of the tumor cells considerably altering the patient's state of health unlike patients in the early stages where the tumor cells are limited. within the originating organ.

In univariate analysis, the type of surgery was a prognostic factor $(\mathrm{p}<0.001)$, unlike Yeboah et al. in Ghana in $2018(\mathrm{p}=0.640)$ who did not find any significant difference in survival between operated and non-operated patients [31]. This could be explained on one hand by the fact that almost half of the patients 
in its population were operated on urgently and on the other hand by the quality of the surgery where a good number of patients had invaded resection margins.

\section{Limitations of the Study}

Our study being retrospective, we were confronted with several difficulties. The main difficulty encountered in our study resided in the fact that many patient files were either not found or unusable due to missing essential information, thus considerably reducing the size of our sample during the analysis of the various variables and therefore the quality and the strength of our results. A good number of patients could not be included in the study or were not taken into account at certain levels of the analysis because they were lost in sight during their follow-up, thus compromising the interpretation of the results linked to survival and identification of more prognostic factors. Since all of our patients were not followed for the same period, it therefore became difficult to assess the secondary appearance of metachronous metastases or the occurrence of recurrence as a prognostic factor. The non-uniformity of treatment protocols administered to patients according to their stage and clinical condition considerably altered the analysis and the interpretation of the impact of chemoradiation therapy. The majority of our patients did not benefit from staging before their treatment, which does not allow a fair appreciation of the impact of the treatment according to the patient's condition and harmonization of treatment protocols.. Few patients have benefited from a pre-therapeutic dosage of the ACE rate, a prognostic mark however recommended for patient monitoring.

The main strength of our study was the research and identification of prognostic factors that will certainly allow a better assessment of the patient during his management. Another strength of our study resided in the comparison and search for associations between the different socio-demographic, clinical, therapeutic and evolutionary characteristics and the tumor location because although colorectal cancer is presented as a unique nosological entity, it nonetheless remains true that both colon cancer and rectal cancer have particularities that we have tried to highlight unlike most descriptive studies on colorectal cancer. Taking into account the various missing data and those lost to follow-up in the analysis thus increases the reliability of our results, which is not the case in certain survival studies where the lost to follow-up were considered dead.

\section{Conclusion}

Colorectal cancer is a common pathology in our community. The prognosis of this disease in the medium and long term was poor with an overall survival at 1 year, 3 years and 5 years respectively of $79.6 \%, 46.3 \%$, and $12.2 \%$ and a median survival of 43 months. In univariate analysis, the degree of differentiation, lymph node involvement, type of surgery and carcinologic stage were significant prognostic factors and in multivariate analyzes, the low degree of differentiation, the presence of synchronous metastases (Stage IV) were factors independent of poor 
prognosis unlike curative surgery which was an independent factor of good prognosis.

\section{Conflicts of Interest}

The authors declare no conflicts of interest regarding the publication of this paper.

\section{References}

[1] Bray, F., Ferlay, J., Soerjomataram, I., Siegel, R.L., Torre, L.A. and Jemal, A. (2018) Global Cancer Statistics 2018: GLOBOCAN Estimates of Incidence and Mortality Worldwide for 36 Cancers in 185 Countries. CA: A Cancer Journal for Clinicians, 68, 394-424. https://doi.org/10.3322/caac.21492

[2] Torre, L.A., Bray, F., Siegel, R.L., Ferlay, J., Lortet-Tieulent, J. and Jemal, A. (2015) Global Cancer Statistics, 2012. CA: A Cancer Journal for Clinicians, 65 87-108. https://doi.org/10.3322/caac.21262

[3] Ferlay, J., Shin, H.-R.R., Bray, F., Forman, D., Mathers, C. and Parkin, D.M. (2010) Estimates of Worldwide Burden of Cancer in 2008: GLOBOCAN 2008. International Journal of Cancer, 127, 2893-2917. https://doi.org/10.1002/ijc.25516

[4] Ferlay, J., Soerjomataram, I., Dikshit, R., Eser, S., Mathers, C., Rebelo, M., Parkin, D.M., Forman, D. and Bray, F. (2015) Cancer Incidence and Mortality Worldwide: Sources, Methods and Major Patterns in GLOBOCAN 2012. International Journal of Cancer, 136, E359-E386. https://doi.org/10.1002/ijc.29210

[5] Douaiher, J., Ravipati, A., Grams, B., Chowdhury, S., Alatise, O. and Are, C. (2017) Colorectal Cancer-Global Burden, Trends, and Geographical Variations. Journal of Surgical Oncology, 115, 619-630. https://doi.org/10.1002/jso.24578

[6] Global Burden of Disease Cancer Collaboration, Fitzmaurice, C., Abate, D., Abbasi, N., Abbastabar, H., Abd-Allah, F., Abdel-Rahman, O., et al. (2019) Global, Regional, and National Cancer Incidence, Mortality, Years of Life Lost, Years Lived with Disability, and Disability-Adjusted Life-Years for 29 Cancer Groups, 1990 to 2017: A Systematic Analysis for the Global Burden of Disease Study. JAMA Oncology, 5, 1749-1768. Erratum in: (2020) JAMA Oncology, 6, 444; Erratum in: (2020) JAMA Oncology, 6, 789.

[7] Murphy, G., Devesa, S.S., Cross, A.J., Inskip, P.D., McGlynn, K.A. and Cook, M.B. (2011) Sex Disparities in Colorectal Cancer Incidence by Anatomic Subsite, Race and Age. International Journal of Cancer, 128, 1668-1675. https://doi.org/10.1002/ijc.25481

[8] Imad, F.E., Drissi, H., Tawfiq, N., Bendahhou, K., Jouti, N.T., Benider, A., et al. (2019) Epidemiological, Nutritional and Anatomopathological Features of Patients with Colorectal Cancer in the Greater Casablanca Region. The Pan African Medical Journal, 32, 56. https://doi.org/10.11604/pamj.2019.32.56.10548

[9] Astin, M., Griffin, T., Neal, R.D., Rose, P. and Hamilton, W. (2011) The Diagnostic Value of Symptoms for Colorectal Cancer in Primary Care: A Systematic Review. British Journal of General Practice, 61, e231-e243. https://doi.org/10.3399/bjgp11X572427

[10] (2014) German Guideline Program in Oncology. Evidenced-Based Guideline for Colorectal Cancer. Awmf, 1-251.

[11] Puddu, M. and Tafforeau, J. (2006) Cancer Colorectal. Etat des connaissances et données disponibles pour le développement d'une politique de santé en Belgique, 
2006-023:80.

[12] Haute Autorité de Santé (2008) Cancer Colorectal. Guide-Affection Longue Durée, 36.

[13] Bibeau, F., Hazebroucq, J., Pierson, R. and Khellaf, L. (2013) Facteurs pronostiques des cancers colorectaux localisés. Colon and Rectum, 7, 134-142. https://doi.org/10.1007/s11725-013-0469-3

[14] Mitry, E. and Rachet, B. (2006) Pronostic des cancers colorectaux et inégalités socio-économiques. Gastroentérologie Clinique et Biologique, 30, 598-603. https://doi.org/10.1016/S0399-8320(06)73234-1

[15] Bostwick, D.G., Grignon, D.J., Hammond, M.E.H., Amin, M.B., Cohen, M., Crawford, D., et al. (2000) Prognostic Factors in Prostate Cancer: College of American Pathologists Consensus Statement 1999. Archives of Pathology \& Laboratory Medicine, 124, 995-1000. https://doi.org/10.5858/2000-124-0995-PFIPC

[16] Vîlcea, I., Romain, B., Rohr, S. and Burcoae, T. (2018) Prognostic Factors Analysis for Colon Cancer with Lymph Node Negative. Chirurgia, 113, 503-515. https://doi.org/10.21614/chirurgia.113.4.503

[17] Jemal, A., Clegg, L.X., Ward, E., Ries, L.A.G., Wu, X., Jamison, P.M., et al. (2004) Annual Report to the Nation on the Status of Cancer, 1975-2001, with a Special Feature Regarding Survival. Cancer, 101, 3-27. https://doi.org/10.1002/cncr.20288

[18] Boyle, P. and Langman, M.J.S. (2000) ABC of Colorectal Cancer: Epidemiology. BMJ, 321, 805-808. https://doi.org/10.1136/sbmj.0012452

[19] Parkin, D.M., Bray, F., Ferlay, J. and Pisani, P. (2005) Global Cancer Statistics, 2002. CA: A Cancer Journal for Clinicians, 55, 74-108. https://doi.org/10.3322/canjclin.55.2.74

[20] Fathi, S.S. (2013) Survie et pronostique des patients opérés pour de cancer du rectum. Thèse de doctorat en medicine, Université de Mohamed V-Souissi, Maroc.

[21] Enow, O.G.E., Ndom, P. and Doh, A.S. (2012) Current Cancer Incidence and Trends in Yaounde, Cameroon. Oncology, Gastroenterology and Hepatology Reports, 1, 5863. https://doi.org/10.4103/2348-3113.133639

[22] Engbang, J., Fewou, A., Hasigov, A., Njel, O., Djougmo, B., Ateba, R., et al. (2018) Colon Cancers: Epidemiological and Histopathological Aspects in Cameroon. Journal of Cancer and Tumor International, 7, 1-13. https://doi.org/10.9734/JCTI/2018/38860

[23] Ngo-Nonga, B., Mouafo Tambo, F., Farikou, I., Fouda, J.P., Ngowe Ngowe, M., Bahebeck, J., et al. (2011) Problématique du traitement du cancer rectal localement invasif dans un pays avec des ressources médicales limitées. Louvain Médical, 130, 349-352.

[24] Mesli, S.N., Regagba, D., Tidjane, A. and Abi-Ayad, C. (2016) Analyse des facteurs histo-pronostiques du cancer du rectum non métastatique dans une série ouest Algérienne de 58 cas au CHU-Tlemcen. The Pan African Medical Journal, 24, 1-7. https://doi.org/10.11604/pamj.2016.24.5.8580

[25] Mehrkhani, F., Nasiri, S., Donboli, K., Meysamie, A. and Hedayat, A. (2009) Prognostic Factors in Survival of Colorectal Cancer Patients after Surgery. Colorectal Disease, 11, 157-161. https://doi.org/10.1111/j.1463-1318.2008.01556.x

[26] Joachim, C., Macni, J., Drame, M., Pomier, A., Escarmant, P., Veronique-Baudin, J., et al. (2019) Overall Survival of Colorectal Cancer by Stage at Diagnosis: Data from the Martinique Cancer Registry. Medicine, 98, e16941. https://doi.org/10.1097/MD.0000000000016941 
[27] Shan, T., Chen, S., Chen, X., Lin, W., Li, W., Ma, J., et al. (2019) Association of Family History of Tumors with Clinicopathological Characteristics and Prognosis of Colorectal Cancer. European Journal of Cancer Prevention, 28, 258-267. https://doi.org/10.1097/CEJ.0000000000000482

[28] Spano, J.P., Lagorce, C., Atlan, D., Milano, G., Domont, J., Benamouzig, R., et al. (2005) Impact of EGFR Expression on Colorectal Cancer Patient Prognosis and Survival. Annals of Oncology, 16, 102-108. https://doi.org/10.1093/annonc/mdi006

[29] Carlomagno, C., De Stefano, A., Rosanova, M., De Falco, S., Attademo, L., Fiore, G., et al. (2019) Multiple Treatment Lines and Prognosis in Metastatic Colorectal Cancer Patients. Cancer and Metastasis Reviews, 38, 307-313. https://doi.org/10.1007/s10555-018-9748-7

[30] Arfa, N., Hamdani, I., Gharbi, L., Ben Abid, S., Ghariani, B., Mannai, S., et al. (2006) Survie et facteurs pronostiques des adénocarcinomes colorectaux: Étude analytique uni-et multifactorielle de 150 cas. Annales de Chirurgie, 131, 104-111.

https://doi.org/10.1016/j.anchir.2005.12.012

[31] Agyemang-Yeboah, F., Yorke, J., Obirikorang, C., Batu, E.N., Acheampong, E., Frimpong, E.A., et al. (2018) Colorectal Cancer Survival Rates in Ghana: A Retrospective Hospital-Based Study. PLoS ONE, 13, e0209307.

https://doi.org/10.1371/journal.pone.0209307

[32] Chou, C.L., Tseng, C.J. and Shiue, Y.L. (2017) The Impact of Young Age on the Prognosis for Colorectal Cancer: A Population-Based Study in Taiwan. Japanese Journal of Clinical Oncology, 47, 1010-1018. https://doi.org/10.1093/jico/hyx110

[33] Pita-Fernández, S., González-Sáez, L., López-Calviño, B., Seoane-Pillado, T., Rodríguez-Camacho, E., Pazos-Sierra, A., et al. (2016) Effect of Diagnostic Delay on Survival in Patients with Colorectal Cancer: A Retrospective Cohort Study. BMC Cancer, 16, Article No. 664. https://doi.org/10.1186/s12885-016-2717-z

[34] Gbessi, D.G., Seto, D.M., Antidehou, S.L., Lawani, I., et al. (2015) Facteurs pronostiques de mortalite precoce dans les cancers colo-rectaux au benin. Le Bénin Médical, 21-26.

[35] Ouedraogo, S., Tapsoba, T.W., Bere, B., Ouangre, E. and Zida, M. (2019) Epidemiology, Treatment and Prognosis of Colorectal Cancer in Young Adults in Sub-Saharan Africa. Bulletin du Cancer, 106, 969-974. https://doi.org/10.1016/j.bulcan.2019.08.021

[36] Kwon, H.C., Kim, S.H., Oh, S.Y., Lee, S., Lee, J.H., Choi, H.J., et al. (2012) Clinical Significance of Preoperative Neutrophil-Lymphocyte versus Platelet-Lymphocyte Ratio in Patients with Operable Colorectal Cancer. Biomarkers, 17, 216-222. https://doi.org/10.3109/1354750X.2012.656705

[37] Tamakoshi, A., Nakamura, K., Ukawa, S., Okada, E., Hirata, M., Nagai, A., et al. (2017) Characteristics and Prognosis of Japanese Colorectal Cancer Patients: The BioBank Japan Project. Journal of Epidemiology, 27, S36-S42. https://doi.org/10.1016/j.je.2016.12.004

[38] Konaté, I., Sridi, A., Ba, P.A., Cissé, M., Gaye, M., Ka, I., et al. (2012) Étude descriptive des cancers colorectaux à la clinique chirurgicale du CHU Aristide Le Dantec de Dakar. Journal Africain du Cancer, 4, 233-237. https://doi.org/10.1007/s12558-012-0232-y

[39] Chalya, P.L., Mchembe, M.D., Mabula, J., Rambau, P.F., Jaka, H., Koy, M., et al. (2013) Clinicopathological Patterns and Challenges of Management of Colorectal Cancer in a Resource-Limited Setting: A Tanzanian Experience. World Journal of Surgical Oncology, 11, Article No. 88. https://doi.org/10.1186/1477-7819-11-88

[40] Powell, A.G.M.T., Wallace, R., Mckee, R.F., Anderson, J.H., Going, J.J., Edwards, J., 
et al. (2012) The Relationship between Tumour Site, Clinicopathological Characteristics and Cancer-Specific Survival in Patients Undergoing Surgery for Colorectal Cancer. Colorectal Disease, 14, 1493-1499.

https://doi.org/10.1111/j.1463-1318.2012.03048.x

[41] Zou, Z.Y., Liu, H.L., Ning, N., Li, S.Y., Du, X.H. and Li, R. (2016) Clinical Significance of Pre-Operative Neutrophil Lymphocyte Ratio and Platelet Lymphocyte Ratio as Prognostic Factors for Patients with Colorectal Cancer. Oncology Letters, 11, 2241-2248. https://doi.org/10.3892/ol.2016.4216

[42] Rosenberg, R., Friederichs, J., Schuster, T., Gertler, R., Maak, M., Becker, K., et al. (2008) Prognosis of Patients with Colorectal Cancer Is Associated with Lymph Node Ratio a Single-Center Analysis of 3026 Patients over a 25-Year Time Period. Annals of Surgery, 248, 968-977. https://doi.org/10.1097/SLA.0b013e318190eddc 